
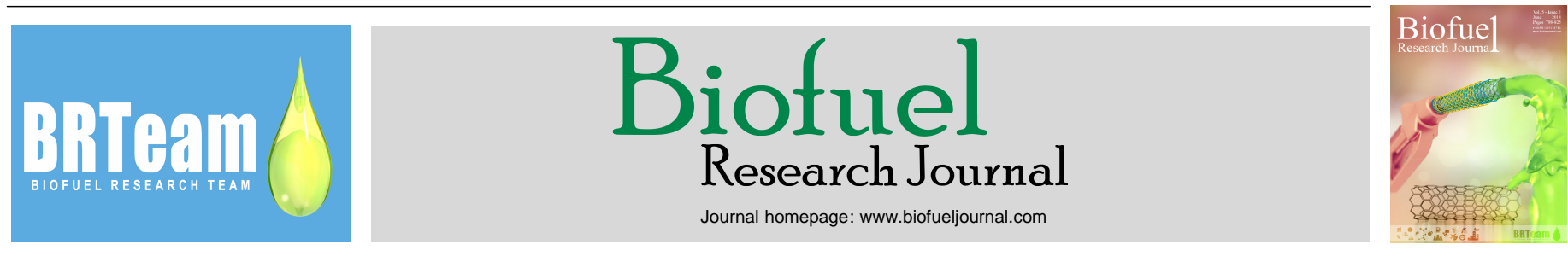

Original Research Paper

\title{
Green diesel production through simultaneous deoxygenation of palmitic acid and desulfurization of 4,6-Dimethyl-dibenzothiophene over commercial $\mathrm{CoMo} / \mathrm{Al}_{2} \mathrm{O}_{3}$
}

Sunya Boonyasuwat*, Jirdsak Tscheikuna

Chemical Engineering Department, Faculty of Engineering Chulalongkorn University Bangkok 10330, Thailand.

\section{HIGHLIGHTS}

$>4,6$-di-methyl-di-benzothiophene was used as a sulfur-containing light gas oil.

$>$ Deoxygenation of palmitic acid led to approx. $100 \%$ conversion at reaction temperature of $300{ }^{\circ} \mathrm{C}$ in the presence of 4,6-di-methyl-di-benzothiophene. $>$ The formation of heavy products and lack of sulfur caused a gradual pressure drop over time.

$>$ The best reagent for $\mathrm{CoMo} / \mathrm{Al}_{2} \mathrm{O}_{3}$ reactivation was dimethyl-disulfide.

\section{GRAPHICAL ABSTRACT}

\section{ARTICLE INFO}

\section{Article history:}

Received 17 March 2018

Received in revised form 29 April 2018

Accepted 29 April 2018

Available online 1 June 2018

\section{Keywords:}

Palmitic Acid

Co-processing

Deoxygenation

Desulfurization

Hydrotreating catalyst

$\mathrm{CoMo} / \mathrm{Al}_{2} \mathrm{O}_{3}$

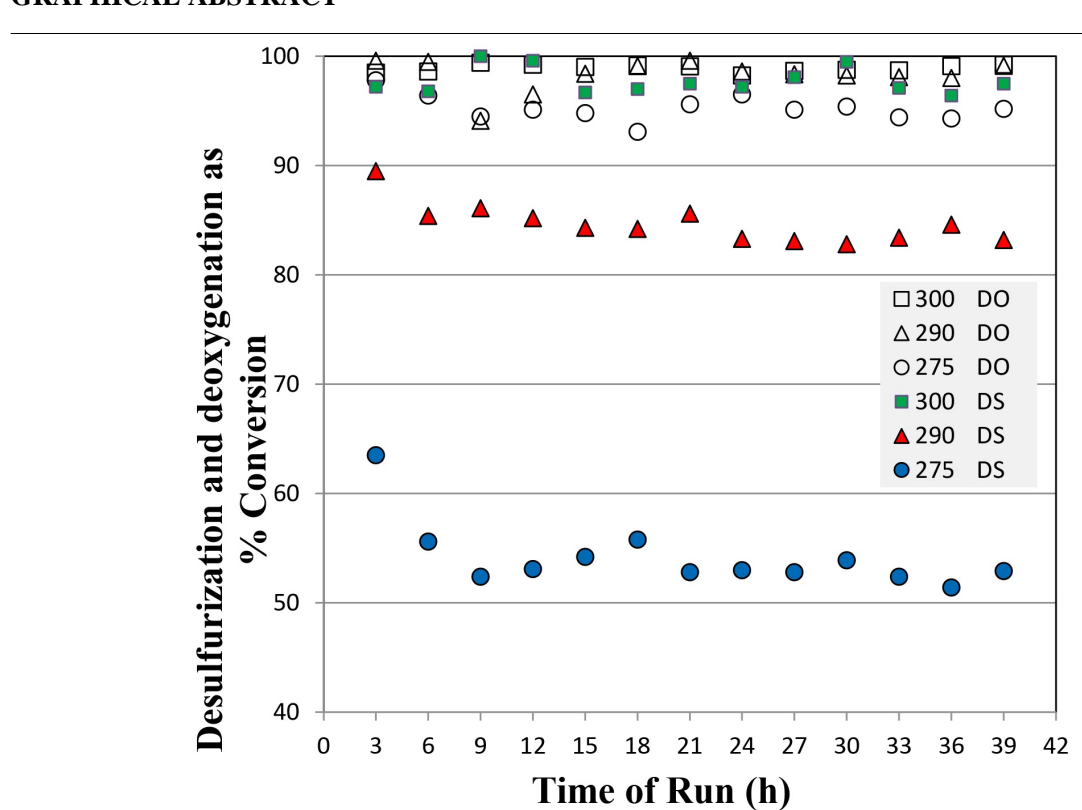

\begin{abstract}
This study investigated the deoxygenation of palmitic acid as a model compound of palm fatty acid distillate (PFAD), in the presence of 4,6- di-methyl-di-benzothiophene as a sulfur-containing light gas oil (LGO). Reactions were performed at the pressure of $25 \mathrm{barg}$, liquid hourly space velocity (LHSV) of $1.7 \mathrm{~h}-1$, and $\mathrm{H}_{2} /$ oil of $630 \mathrm{NL} / \mathrm{L}$ over $\mathrm{CoMo} / \mathrm{Al}_{2} \mathrm{O}_{3}$ as catalyst. The effect of temperature was studied in the range of $275-300{ }^{\circ} \mathrm{C}$. Both deoxygenation and desulfurization led to approximately $100 \%$ conversions at $300{ }^{\circ} \mathrm{C}$, while at $275^{\circ} \mathrm{C}$, palmitic acid deoxygenation was recorded at a higher conversion rate compared with that of the desulfurization of 4,6- di-methyl-di-benzothiophene. The presence of 4,6- di-methyl-di-benzothiophene during the deoxygenation of palmitic acid resulted in high conversions (>95\%). Pressure drop studies showed that the formation of heavy products caused a gradual pressure drop throughout the reactor over time. The catalyst was deactivated during $10 \mathrm{~d}$. Two different sulfur-containing reagents were used for catalyst reactivation including dimethyl-disulfide in n-C18 and LGO containing 484 ppmw of sulfur. Reactivation with $2 \mathrm{wt} . \%$ of dimethyl-disulfide in $\mathrm{n}-\mathrm{C} 18$ at $320^{\circ} \mathrm{C}$ for $36 \mathrm{~h}$ led to more favrable performance recovery $v s$. the sulfur-containing LGO.
\end{abstract}

(C) 2018 BRTeam. All rights reserved.

Corresponding author at: Tel.: +66 814032723

E-mail address: sunyabb@gmail.com

Please cite this article as: Boonyasuwat S., Tscheikuna J. Deoxygenation and Desulfurization of Palmitic Acid with 4,6-Dimethyl dibenzothiophene in Noctadecane as a Model Study for Palm Fatty Acid Distillate in Light Gas Oil over Commercial CoMo/ $\mathrm{Al}_{2} \mathrm{O}_{3}$. Biofuel Research Journal 18 (2018) 821-826. DOI: 10.18331/BRJ2018.5.2.6 


\section{Introduction}

In recent decades, unpredictable crude oil prices and the consequent environmental issues attributed to the widespread utilization of these resources have encouraged large demands for cleaner alternative fuels (Huber et al., 2006). Since commercial diesel already has to contain at least $7 \%$ biodiesel in the European countries, the future of biofuel industries looks more promising for the next generation of alternative diesel fuels. The EU`s Renewable Energy Directive (RED) also launched a policy to further stimulate the increase in production and promotion of energy from renewable sources to 900 million tons accounting for $20 \mathrm{wt} . \%$ biofuel in fuel blends by the year 2020. The commission also proposed that the target for renewables in the final energy consumption in the EU be set at $27 \%$ by 2030 to (Renewable Energy Directive, 2009; Innovation Union, 2014). In addition, according to the RED article 21 requirement (Renewable Energy Directive, 2009); contributions will be double-counted when biofuels are produced from wastes or residues (Henk, 2017). In order to reach the aim of the RED proposal, various kinds of waste materials have been recently investigated for the production of biofuels, i.e., second-generation biofuels. These have also been known as advanced biofuels synthesized from biomass, agricultural residues, and wastes, e.g. lingocellulosic ethanol, pyrolysis of biomass to bio-oil, and hydrogenation of fats and oils to diesel-like hydrocarbons.

Many research attempts are currently underway focusing on hydrodesulfurization or hydrotreating process using different sources of triglycerides including waste lipids, waste cooking oil, and municipal trapped greases (Graham-wood, 2008; Bezerganni et al., 2010). Biofuels from these wastes can be processed via two routes. First, the conventional and convenient route for the production of renewable diesel, i.e., transesterification and esterification of triglycerides (oils and fats) and their derivatives including waste materials from vegetable oil processing and used cooking oil. This process also involves a short chain alcohol (methanol or ethanol) and an acid or base catalyst to obtain a mixture of fatty acid methyl esters, also known as biodiesel (Hawash et al., 2011). The more advanced processing route is the hydroconversion of similar feedstock to more fungible fuel, i.e., "green diesel", which is a mixture of oxygen-free hydrocarbons. Impressively, green diesel has similar molecular structures to conventional diesel. The former process leading to biodiesel production is claimed to result in many negative effects, e.g., impaired cold flow properties and poor storage stability, while the renewable diesel has been proven to provide a more advantageous fuel due to its higher stability, cleaner burning, and higher cetane number, resulting in higher blending proportions with conventional diesel (Mikkonen, 2008; Egeberg, 2010; Santill and Crocker, 2012; Sotelo et al., 2012).

Hydroconversion technology requires high temperature and pressure, safety awareness, and advanced catalysis understanding. Moreover, the availability of the technology, catalysts, and hydrogen widely used in hydrotreating and hydrodesulfurization units in complex oil refineries are major parameters marking this route favorable. The research on the production of renewable diesel has consequently received much attention in many oil refineries. Due to the fact that oil refineries can readily utilize the existing hydrotreater/hydrodesulfurization units, standalone and co-processing of renewable feedstock with petroleum intermediates have been widely studied (Santill and Crocker, 2012; Jeczmionek and Porzycka, 2014). However, the investment cost of a standalone hydroprocessing unit for vegetable oil is so high supporting a co-processing solution as a much more attractive strategy. Moreover, green diesel from hydroconverted oils, fat, and derivatives is finally required to be blended with conventional diesel to meet EN 590 automotive diesel specification. These support the effort of many refineries and researchers in developing renewable diesel production by exploring the potential of coprocessing technique with petroleum intermediates in their existing units (Monnier et al., 1998; Huber and Corma, 2007; Graham-wood, 2008).

In our previous work, the co-processing technique was investigated through the co-processing of commercial palm fatty acid distillate (PFAD) with light gas oil (LGO) containing $545 \mathrm{ppm}$ sulfur in a pilot-scale hydrotreating unit (Boonyasuwat and Tscheikuna, 2017). Despite the promising results obtained, several technical concerns could still be raised by on-site engineers and operators, e.g. the catalyst lifetime and deactivation, catalyst reactivation technique, and the improvement of the reactor and the process for better process control. More specifically, the first concern was catalyst deactivation which might occur by the incident of lacking of hydrogen sulfide and low sulfurcontaining feed in gas and liquid phases, respectively. Moreover, high purging rate of gas stream from the reactor effluent due to the formation of byproduct gases, i.e., $\mathrm{CO}$, and $\mathrm{CO}_{2}$ in large amounts, and an increase of hydrogen making-up rate to maintain the hydrogen purity in the reactor were observed. These resulted in a lack of hydrogen sulfide in the hydrogen-rich gas phase, which is well known for maintaining catalyst activity during co-processing. Second technical concern was the quenching stream of feed and/or hydrogen between reactor beds or a series of reactors, in order to control the reactor temperature due to highly exothermic reaction of hydrogenation and deoxygenation reactions. The upper layer of the catalyst bed, which was located below the quenching zone, might have lower temperatures than the other part of the catalyst. This volume of the catalyst would then encounter poor operating conditions (lacking of $\mathrm{H}_{2} \mathrm{~S}$ ), and low reaction temperature $\left(270-300^{\circ} \mathrm{C}\right)$. The third technical concern was the pressure drop across the whole reactor leading to slight decreases in catalyst volume especially at low temperature zones. Consequently, it was necessary to understand the degree of the catalyst deactivation at poor conditions, low temperature behavior, as well as the pressure drop across the low-temperature reaction zone. In addition, the catalyst reactivation method was needed to be investigated.

Therefore, in the present study, the above-mentioned concerns were addressed using model compounds in order to avoid unknown factors associated with the impurities in PFAD and LGO. For instance, gum and sodium in PFAD might deactivate the catalyst. A high refractory sulfur component was used to determine desulfurization activity. More specifically, palmitic acid was selected as a model of PFAD, and 4,6-dimethyl-di-benzothiophene (4,6-DMDBT) with n-octadecane (n-C18) was prepared as sulfur-containing LGO. The reactor conditions were simulated as present in the poor condition zone of the pilot-scale reactor in our previous experiment, i.e., $270-300{ }^{\circ} \mathrm{C}$ and 25 barg. The effect of deoxygenation on desulfurization was studied and visa versa. The deactivation of the catalyst when co-processing model compounds was evaluated by various concentrations of palmitic acid and 4,6-DMDBT in $n$ octadecane. Long time deactivation profile was also investigated using 10 wt. $\%$ palmitic acid and 4,6-DMDBT containing $180 \mathrm{ppm}$ sulfur. Moreover, the reactivation of the catalyst was also studied by using plausible and economical solutions. It should be highlighted that although the production of green diesel by co-processing has already been well studied and proven to meet the diesel EN 590 specification, only few studies have paid attention to the effect of renewable feed on desulfurization reaction and vice versa as well as to catalyst deactivation and reactivation techniques at poor conditions.

\section{Materials and Methods}

\subsection{Catalyst and feed preparation and analysis}

The catalyst used in this study was a commercial hydrotreating catalyst, $\mathrm{CoMo} / \mathrm{Al}_{2} \mathrm{O}_{3}$ and was the same as the one used in our previous work (Boonyasuwat and Tscheikuna, 2017). The catalysts were analyzed by energy-dispersive $\mathrm{x}$-ray (EDS) spectroscopy as shown in Table 1 . The catalyst size was $1.3 \mathrm{~mm}$ in diameter and $4-8 \mathrm{~mm}$ in length.

Table 1.

The results of the energy-dispersive X-ray spectroscopy analysis of the different catalysts used in this study.

\begin{tabular}{lllllll}
\hline \multirow{2}{*}{ Catalyst } & \multicolumn{6}{c}{ Element (wt.\%) } \\
\cline { 2 - 7 } & C & O & Al & P & Co & Mo \\
\hline Spectrum 1 & 2.73 & 53.65 & 27.73 & 3.32 & 1.70 & 10.86 \\
Spectrum 2 & 2.91 & 53.61 & 25.97 & 3.28 & 2.10 & 12.13 \\
Spectrum 3 & 2.73 & 54.20 & 26.95 & 3.00 & 1.87 & 11.28 \\
Spectrum 4 & 3.68 & 55.57 & 26.38 & 2.89 & 1.54 & 9.94 \\
Spectrum 5 & 3.08 & 56.27 & 25.77 & 2.97 & 1.50 & 10.41 \\
\hline Average & 3.03 & 54.66 & 26.56 & 3.09 & 1.74 & 10.92 \\
S.D. & 0.39 & 1.20 & 0.79 & 0.19 & 0.25 & 0.84 \\
\hline
\end{tabular}


A commercial grade palmitic acid 99.9 wt.\% was used. N-octadecane 99 wt.\% as a model LGO was obtained from Sigma-Aldrich (Germany). The model sulfur component in LGO was 4,6 dimethyl-dibenzothiophene (4,6DMDBT) 99.99 wt.\% was also obtained from Sigmal-Aldrich (Germany). Palmitic acid was melted and pre-mixed with n-octadecane at 5, 10, and 20 wt.\% at heated at $50{ }^{\circ} \mathrm{C}$ for complete dissolution. 4,6-DMDBT was then slightly added to the mixture to $178-183$ ppmw of total sulfur. The amount of palmitic acid was analyzed by the titrimetric method using $0.1 \mathrm{~N}$ of $\mathrm{NaOH}$ solution. The total sulfur content in both products and feeds were measured using a LABX3000 x-ray fluorescence (XRF) analyzer (Oxford Instrument Company Ltd., Osney Mead, Oxford) and pre-heated samples $\left(45^{\circ} \mathrm{C}\right)$ for preventing solidification of palmitic acid.

\subsection{Experimental setup and procedure}

The reaction was conducted in a laboratory scale fixed-bed tubular reactor. The process diagram was shown in Figure 1. The reactor was a $316 \mathrm{~L}$ stainless steel tube, $1 / 2$ inch $\mathrm{OD}$, and $50 \mathrm{~cm}$ of total length. A type-K thermocouple with $1 / 16$ " OD was inserted from the bottom of the reactor, more specifically, in the middle of the catalyst bed. The catalyst was loaded between two packs of glass wool and between two stacks of glass beads, respectively. The height of the catalyst bed was approximately $4 \mathrm{~cm}$ and was assumed to be a trickle bed with a uniform temperature distribution. Trickle-bed scheme was formed using the catalyst particles, crushed and sieved between 0.8 to $2 \mathrm{~mm}$ in diameter.

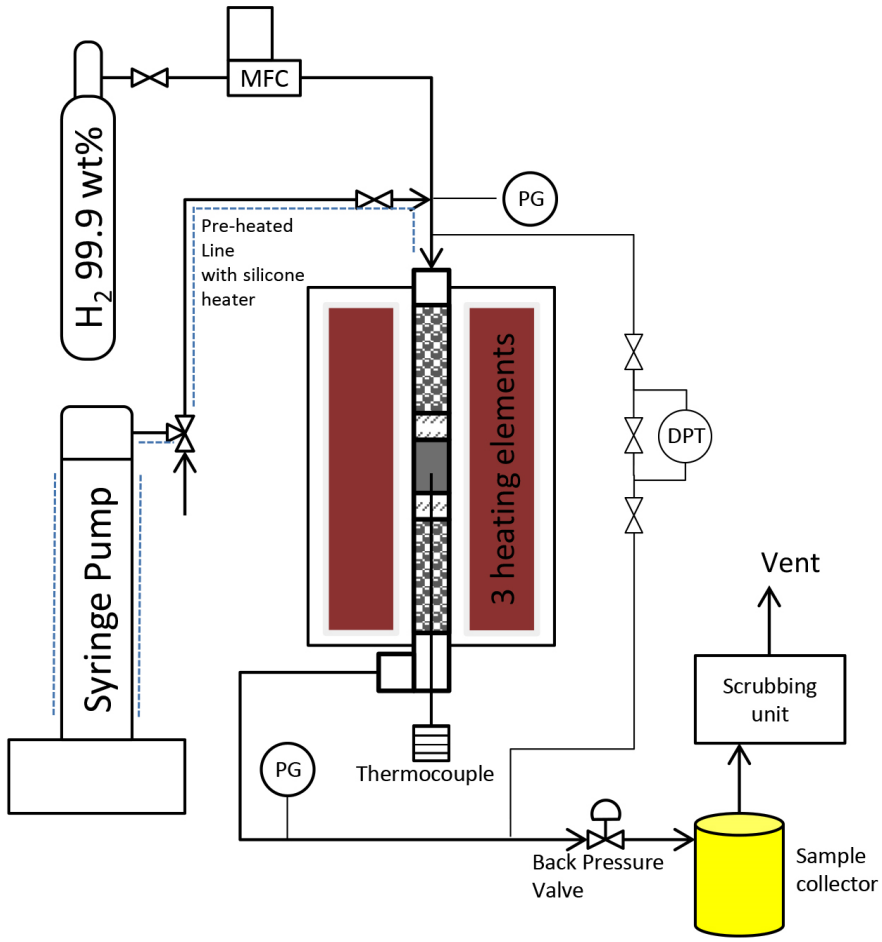

Fig.1. Simplified process scheme and equipment $(\mathrm{PG}=$ pressure gauge, $\mathrm{DPT}=$ differential pressure transmitter, and MFC $=$ mass flow controller).

The reactor temperature was controlled by a temperature controller including heating elements $(3000 \mathrm{~W})$. The feed was preheated at $80{ }^{\circ} \mathrm{C}$ by a silicone heating element located at the wall of the syringe pump (Teledyne ISCO 500D) and was injected to the reactor at $0.2 \mathrm{~mL} / \mathrm{min}(12 \mathrm{~mL} / \mathrm{h}$ or $10 \mathrm{~g} / \mathrm{h}$ of the feedstock). The feed injection line was stainless steel with $1 / 8^{\prime \prime}$ in diameter, and was covered with a silicone electrical preheater to prevent solidification of palmitic acid. Moreover, the end of the feed tube was heated to $200{ }^{\circ} \mathrm{C}$ with an electrical preheater before entering the top of the reactor. The reactor effluent was naturally cooled down to room temperature with a $60 \mathrm{~cm}$ stainless steel bared tube (1/4" OD) before flowing to the back pressure regulating valve. The valve was capable of steadily holding the system pressure, while the effluent flow rate was dependent on the inlet flow rate.

Hydrogen gas 99.9 wt.\% was fed co-currently with liquid feed from the top of the reactor and its flow rate was controlled by a mass flow controller at the inlet port of the reactor. The gas flow rate was controlled at $630 \mathrm{NL} / \mathrm{L}$ $(126 \mathrm{~mL} / \mathrm{min}$ at standard temperature and pressure). Feed inlet pressure was controlled at $25-25.5$ barg. Two pressure gauges and high resolution differential pressure transmitters (Azbil-GTX31D) were installed at the inlet and outlet of the reactor. The liquid samples were collected at the outlet of the back pressure valve, while the gas phase was scrubbed before venting off to the atmosphere.

The catalyst was sulfided prior to the experiment to obtain active sulfided state by in-situ activation using 1.8 wt.\% of dimethyl-disulfide (DMDS) in LGO. The temperature program for DMDS sulfidation followed the temperature program suggested by the commercial catalyst supplier. The reactor was raised to $120^{\circ} \mathrm{C}$ under hydrogen to remove adsorbed water, and subsequently to $280{ }^{\circ} \mathrm{C}$ at $10{ }^{\circ} \mathrm{C} / \mathrm{h}$. The reactor temperature was kept at $290^{\circ} \mathrm{C}$ for $6 \mathrm{~h}$ and was then increased to $320^{\circ} \mathrm{C}$ at $15{ }^{\circ} \mathrm{C} / \mathrm{h}$. The final temperature during sulfidation was $320^{\circ} \mathrm{C}$ for $12 \mathrm{~h}$, and the catalyst was then cooled down to the reaction temperature prior to the experiment. Considering the reactor volume and time-space, at least $6 \mathrm{~h}$ was required to reach the steady-state of the reactor after changing the conditions especially after changing feeds. The catalyst amount corresponding to the catalyst bed height of $4 \mathrm{~cm}$ forming a uniform fixedbed flow scheme, was $7 \mathrm{~g}$. The amount of the hydrogen flow rate, liquid rate, and the catalyst was calculated to obtain trickled-bed reaction scheme in the reactor.

\section{Results and Discussion}

\subsection{Catalyst and the reaction conditions}

The catalyst used in this study was a commercial $\mathrm{CoMo} / \mathrm{Al}_{2} \mathrm{O}_{3}$, which was used in our previous work for pilot-scaled production of green diesel by co-processing PFAD and LGO (Boonyasuwat and Tscheikuna, 2017). The catalyst was originally designed to be capable of LGO desulfurization to ultra-low sulfur diesel ( $<15 \mathrm{ppm}$ sulfur) and was proved to be able to deoxygenate up to $25 \mathrm{wt} . \%$ PFAD in LGO to produce renewable diesel meeting EURO IV: EN 590 automotive diesel specification (Boonyasuwat and Tscheikuna, 2017). Types of metal loading onto the catalyst were analyzed by EDS spectroscopy as shown in Table 1 . The average amount of cobalt was 1.74 wt.\%, and that of molybdenum was 10.92 wt.\%. An incorporation of phosphorous at about $3 \mathrm{wt} . \%$ into cobalt-molybdenum active metals was observed. The addition of phosphorus benefits desulfurization activity as a second promoter or a modifier of the catalyst acidity (Iwamoto and Grimblot, 2000; Huirache-acuña et al., 2016).

At the beginning, the reaction temperature was set at $300^{\circ} \mathrm{C}$. Complete deoxygenation of palmitic acid and desulfurization of 4,6-DMDBT was achieved as shown in Figure 2. At low reaction temperatures, the rate of both deoxygenation and desulfurization was adversely affected. To further investigate the impact of temperature, the temperature was reduced from 300 to $275{ }^{\circ} \mathrm{C}$. The results obtained indicated that the decrease of the reaction temperature led to more pronounced negative impact on the desulfurization of 4,6-DMDBT than on the deoxygenation of palmitic acid

Moreover, the impact of pressure reduction in lowering reaction rates was not as significant as that of reaction temperature reduction. More specifically, the decrease in pressure from 30 to 25 barg could only decrease desulfurization conversion by less than a few percentages. The pressure drop across the reactor was also measured by a differential pressure transmitter. Within $42 \mathrm{~h}$ of reaction, the reactor pressure drop varied between 0.040-0.070 bar (resolution of measurement $=0.005$ bar). Temperature variation had no effect on the reactor pressure drop. Hydrogen to feed ratio was controlled at $630 \mathrm{NL} / \mathrm{L}$, which was theoreticallu enough for to achieve both complete desulfurization and deoxygenation. This was the same ratio employed previously for co-processing up to $25 \mathrm{wt} . \%$ PFAD in LGO (Boonyasuwat and Tscheikuna, 2017). In addition, it should be noted that palmitic acid (C16:0) is a saturated fatty acid which certainly consumes less amount of hydrogen than oleic acid and a mixture of fatty acid in PFAD as practiced in the previous study (Boonyasuwat and Tscheikuna, 2017). 


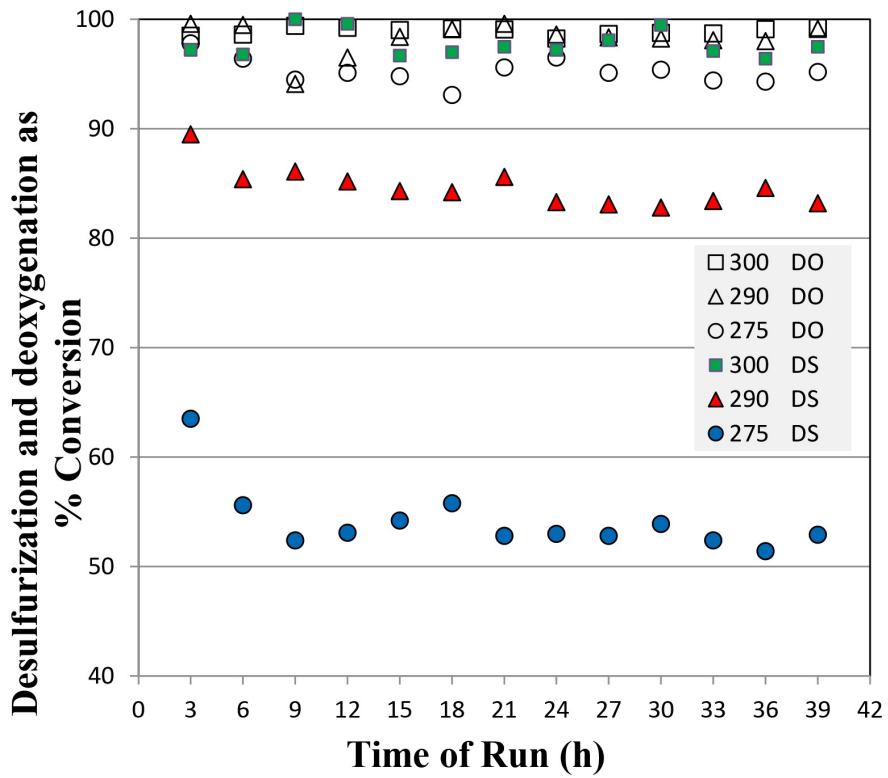

Fig.2. Desulfurization of 4,6-DMDBT and deoxygenation of $10 \mathrm{wt}$ \% palmitic acid at different temperatures, 25 barg, liquid hourly space velocity $(\mathrm{LHSV})=1.7 / \mathrm{h}$, and $\mathrm{H}_{2}$ to oil $=630 \mathrm{NL} / \mathrm{L}$.

\subsection{Effect of palmitic acid}

Palmitic acid was chosen as a model compound representing commercial PFAD usually containing palmitic acid by approximately $45-50 \mathrm{wt} . \%$ (Huber et al., 2006; Boonyasuwat and Tscheikuna, 2017). According to the data presented in Figure 3, the presence of palmitic acid from 0 to 5 and $10 \mathrm{wt} . \%$ slightly decreased desulfurization of 4,6-DMDBT, but the effect of palmitic acid amount was more pronounced when palmitic acid content was increased from 10 to $20 \mathrm{wt} . \%$. These results were similar to those of the study by Templis et al. (2011) who reported that the desulfurization rate of gas oil-palm oil mixture was decreased with the implementation of palm oil to gas oil ration of up to $5 \%$, but there was no further effect when the palm oil content was increased to $10 \%$ at 310,330 , and $350{ }^{\circ} \mathrm{C}$ (Huber et al., 2006). Unlike desulfurization, deoxygenation of palmitic acid was not affected by the amount of palmitic acid. More specifically, the deoxygenation conversion of palmitic acid was decreased by $>2 \%$ in response to increasing palmitic acid content from 5 to $20 \mathrm{wt} . \%$. Even though the reaction temperature was not as high as those reported in most of the research studies (i.e., $300-360{ }^{\circ} \mathrm{C}$ ), a near complete conversion of palmitic acid was achieved at $275{ }^{\circ} \mathrm{C}$ in the present study.

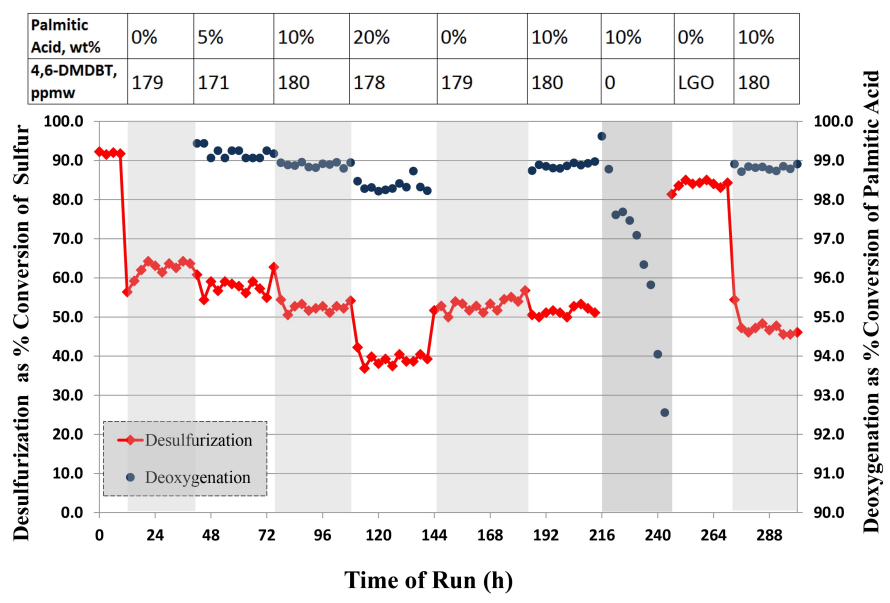

Fig.3. Desulfurization and deoxygenation conversions at various palmitic acid contents while coprocessing with 4,6-DMDBT and n-C18 as model sulfur-containing LGO.
On the other hand, the 4,6-DMDBT desulfurization conversion achieved stood at $40-70 \%$. This was due to the fact that 4,6 -DMDBT is a high refractory sulfur species. Various types of sulfur components in petroleum product are generally classified into different refractory degrees of desulfurization, and a mixture of multi-components are found in LGO Higher refractory sulfur species certainly provide lower desulfurization conversions. It is worth mentioning that prior to using 4,6-DMDBT as a model compound, di-benzothiophene was used and completely desulfurized at $275^{\circ} \mathrm{C}$ (data not shown). This difference could be explained through the steric hindrance between the methyl groups and dibenzothiophene of 4,6-DMDBT. In fact, the two methyl groups in 4,6DMDBT cause a spatial restraining for the adsorption of sulfur atom on the active site of the catalyst, and lead to very low desulfurization reactivity of 4,6-DMDBT. As a result, a high activation energy (i.e., higher temperatures) would be required to increase desulfurization conversion in the presence of 4,6-DMDBT as feedstock (Isoda et al., 1996; Xu et al., 2004).

By introducing palmitic acid into the reaction medium, desulfurization of 4,6-DMDBT took place at a lower rate due to the competitive adsorption and reaction onto the same catalyst active sites. The competitive adsorption of palmitic acid also caused a reversible deterioration of the desulfurization 4,6-DMDBT. The desulfurization was increased after the feed was switched back to 0 wt.\% of palmitic acid. A similar observation was also made by Viljava et al. (2001) when introducing phenol molecules to the hydrodesulfurization of mercaptobenzene in $\mathrm{CoMo} / \mathrm{Al}_{2} \mathrm{O}_{3}$ owing to the strong adsorption of oxygen-containing compound (i.e., phenol). Another factor contributing to the reversible deterioration of the desulfurization 4,6DMDBT in response to the present of palmitic acid could be the formation of water as a by-product of deoxygenation of palmitic acid via hydrodeoxygenation and decarbonylation. Water droplets were also observed during the present experiment, but their quantity was not determined. The amount of water in the products was increased with increasing the palmitic acid content in the feed. It has been proven that water exerts a minor effect leading to the deactivation of the CoMo catalys (Badawi et al., 2011). It should be noted that, water is considered as a weak inhibition and has a low adsorptivity onto the sulfide phase of the CoMo catalyst and therefore, its effect could be reversible (Laurent and Delmon, 1994).

According to Figure 4, varied amounts of palmitic acid had no effect on the reactor pressure drop (reactor pressure ranging from 0.045 to 0.075 bar)

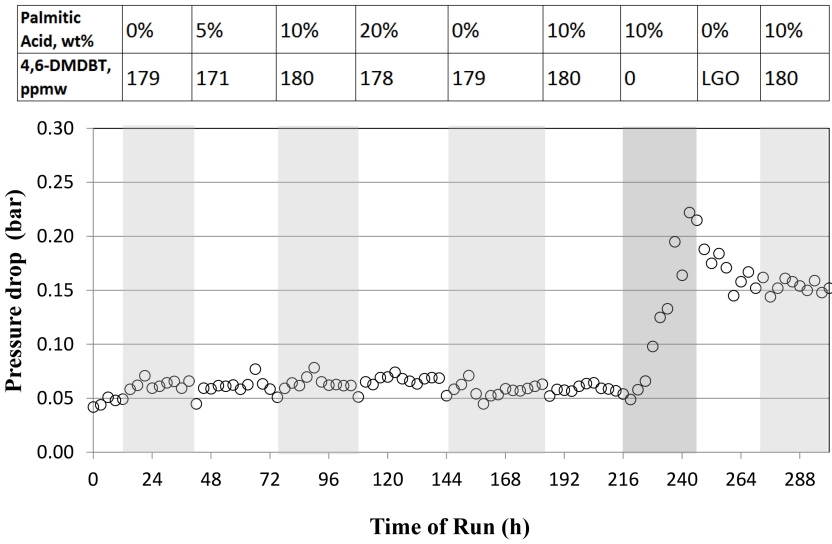

Fig.4. Pressure drop profile in various palmitic acid content while co-processing with 4,6DMDBT and $\mathrm{n}-\mathrm{C} 18$ as a model sulfur-containing LGO.

\subsection{Effect of 4,6-DMDBT}

It was clearly shown that the presence of sulfur in 4,6-DMDBT could enhance the deoxygenation of palmitic acid. High deoxygenation conversion was achieved with very slight deactivation. According to the data presented in Figure 3, the absence of 4,6-DMDBT could severely affect the deoxygenation of palmitic acid. The liquid hydrocarbon products obtained in the absence of 4,6-DMDBT were sampled after $230 \mathrm{~h}$, and were 
black, sticky, and free of any water droplets. On the contrary, the products obtained in the presence of 4,6-DMDBT were physically different, i.e., colorless, low viscosity, containing some droplets of water. The pressure drop between the feed inlet and outlet of the reactor was gradually increased by about 4 times (reaching $0.22 \mathrm{bar}$ ) in the absence of 4,6-DMDBT than that of the normal operation in the presence of 4,6-DMDBT. Moreover, in the absence of 4,6-DMDBT, fatty acid content of the products was recorded higher than 0.7 wt. $\%$ of palmitic acid.

The constituents of the black and sticky sample could be free fatty acids, alcohols, and long chain esters found at low temperature reaction (Snåre et al., 2006; Toba et al., 2010). In fact, reactor temperatures as low as the range practiced in the present study $\left(<300{ }^{\circ} \mathrm{C}\right)$ would not be sufficient for palmitic acid deoxygenation. Therefore, side reactions such as esterification and polymerization to ketones could occur at lower temperatures due to lower activation energy. The formation of by-products through the esterification and polymerization reactions could be so intense blocking catalyst pore, glass wool, and glass bead, resulting in drastic increases in pressure drop across the reactor. The presence of sulfur in 4,6-DMDBT was beneficial for maintaining catalyst sulfide phase and stabilizing deoxygenation conversion of palmitic acid even when the amount of 4,6-DMDBT desulfurized was less than $200 \mathrm{ppm}$. It was also observed that when the catalyst was reactivated by LGO at $254 \mathrm{~h}$ without changing reaction conditions, the performance of both deoxygenation and desulfurization was recovered. The recovery of deoxygenation of palmitic acid was almost complete, but that of desulfurization was only partial. After the catalyst was reactivated by LGO, the product from $10 \%$ palmitic acid and 180 ppm of 4,6-DMDBT was clear, colorless, containing a few droplets of water. During the reactivation step by LGO, desulfurization of LGO reached $85 \%$. This is ascribed to the fact that some of the high desulfurization refractory species could not be converted to sulfur atoms and hydrogen sulfide.

Generally, the sulfur present in the feed could assist with preserving the sulfided phase of the catalyst surface during the reaction. The addition of sulfur could be in various forms, e.g., hydrogen sulfide $\left(\mathrm{H}_{2} \mathrm{~S}\right)$ in gas phase, as well as dimethyl-disulfide (DMDS) and tetra-butyl-amine (TBA) in liquid phase (Bezergianni et al., 2010). Since DMDS has been widely used as a sulfiding agent for catalyst sulfidation and reactivation, many studies have tried to utilize DMDS in standalone processes to stabilize catalyst activity. In a study by Kubicka and Horacek (2011), the co-processing of rapeseed oil with pulsing and continuously fed DMDS could maintain deoxygenation activity. More specifically, an addition of only $0.5 \mathrm{wt} . \%$ DMDS to rapeseed oil improved the catalyst stability by replenishing the depletion of sulfur from the catalyst active site. It was also found out that the addition of DMDS by pulsing could partially restore deoxygenation activity (Kubicka and Horacek, 2011). Nevertheless, it has been reported that the decreases observed in the desulfurization rate could be sometimes irreversible owing to (1) the impurities in the feedstock itself, (2) the strong adsorption of palmitic acid or by-products generated through the side reactions to some catalyst active sites as well as by blocking catalyst pores, and (3) gradual leaching of sulfur, metal oxidation, and metal leaching of active sites (Snåre et al., 2006; Egeberg, 2010; Kubicka and Horacek, 2011; Jeczmionek and Porzycka, 2014).

In the present study, the catalyst performance was obviously increased after performing the reactivation by LGO, but the reactor pressure drop was not improved and the pressure drop was only decreased as much as 07 bar (from 0.22 to 0.15 bar). This finding could be important in terms of safety considerations as well as process pressure control. Moreover, pressure drop could lead to the generation of heavier products causing catalyst pore blockage, as well as blockage at the pack of glass wool and glass beads underneath the catalyst bed. Through the cleaning process performed after the present experiment, a significant amount of polymerized materials trapped inside the stack of glass beads located underneath the pack of glass wool was found.

It should be noted that poor reaction conditions, i.e., low reaction temperature and lack of hydrogen sulfide might occur during process start up or shut down. Under such circumstances, deoxygenation would not be affected but desulfurization would be adversely impacted. To address this challenge, significant amounts of sulfur in feedstock should be considered to maintain catalyst activity. Moreover, feed mixtures containing high refractory sulfur species such as heavy gas oil and heavy vacuum gas oil should be avoided. In this study, it was clearly observed that at least $100 \mathrm{ppmw}$ sulfur released through 4,6-DMDBT desulfurization was sufficient to maintain the catalyst activity while $85 \%$ conversion of LGO containing 484 ppmw sulfur was adequate for the catalyst reactivation.

\subsection{Catalyst deactivation and reactivation}

A slight deactivation of the catalyst was observed over $48 \mathrm{~h}$ of reaction at $275^{\circ} \mathrm{C}$ as revealed by Figures 2 and 3 . When the reaction temperature was higher than $290{ }^{\circ} \mathrm{C}$, the changes in desulfurization activity were not considerable as shown in Figure 2. Deoxygenation of palmitic acid without the presence of sulfur-containing compound was impractical under the studied conditions herein, but as shown in Figure 3, when the reaction was co-processed with sulfur, the catalyst stability was significantly maintained over $48 \mathrm{~h}$ of reaction. Catalyst deactivation during both deoxygenation and desulfurization could be attributed to various factors. For example, alkalis metal, phospholipids, and gumming substances present in palm oi products, e.g., PFAD, could be major causes of catalyst deactivation. In order to exclude these impurities, palmitic acid and 4,6-DMDBT, which are neatly refined products and of analytical grade, were used in this study.
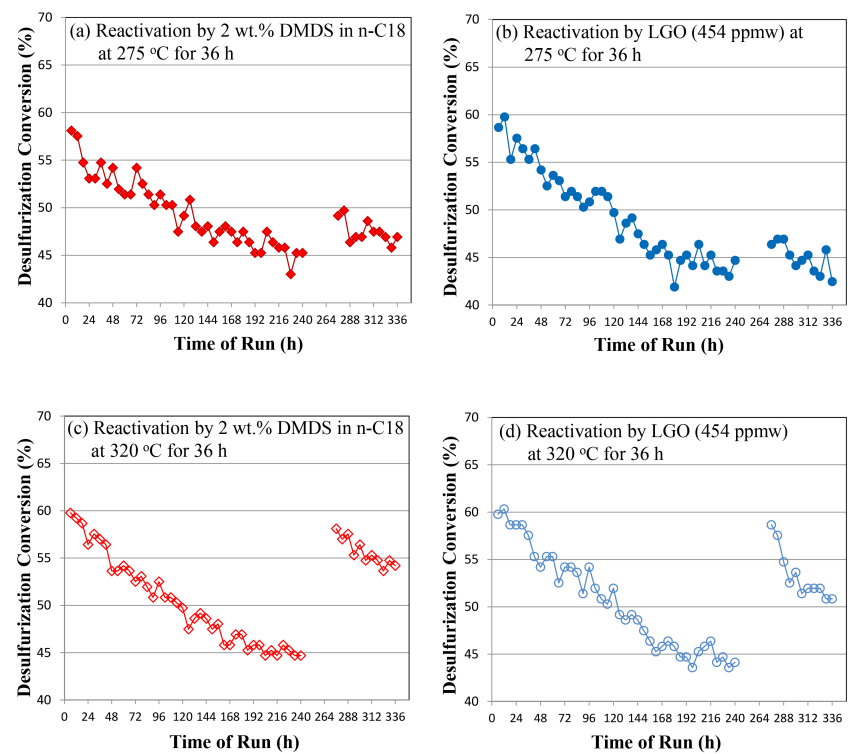

Fig.5. The catalyst deactivation profiles with different reactivation techniques. The reactivation was performed after $240 \mathrm{~h}$

Figure 5 shows the catalyst deactivation profiles using different reactivation techniques. The reactivation was performed after $240 \mathrm{~h}$. The deoxygenation of palmitic acid was not graphically shown because the conversion of palmitic acid was higher than $95 \mathrm{wt} . \%$ at all times of reaction. The deoxygenation conversion was maintained by the presence of sulfur, in this case, 4,6-DMDBT. It was clearly observed that desulfurization conversion was significantly decreased throughout the reaction time of 240 $\mathrm{h}(10 \mathrm{~d})$ (Figure 5). The catalyst used in both desulfurization and deoxygenation was reactivated after $240 \mathrm{~h}$ of reaction. The reactivation step was carried out for $36 \mathrm{~h}$ using different sulfur-containing feedstock, i.e., 2 wt.\% DMDS in n-C18 at $275^{\circ} \mathrm{C}$ (Fig. 5a), LGO with 484 ppmw of sulfur at $275^{\circ} \mathrm{C}$ (Fig. 5b), 2 wt.\% DMDS in n-C18 at $320^{\circ} \mathrm{C}$ (Fig. 5c), and LGO with 484 ppmw of sulfur at $320^{\circ} \mathrm{C}$ (Fig. 5d). It was clearly observed that the reactivating process with DMDS was more advantageous than those with LGO at both 275 and $320{ }^{\circ} \mathrm{C}$. At $320{ }^{\circ} \mathrm{C}$, initial desulfurization conversion of 4,6-DMDBT after reactivation by DMDS and LGO was comparable, but the deactivation profiles were clearly different. The deactivation profile of the desulfurization of 4,6-DMDBT in the case of DMDS at $320{ }^{\circ} \mathrm{C}$ was observed to be slower than that of LGO at the same temperature. Overall, the reactivation by $2 \mathrm{wt} . \%$ DMDS in n-octadecane was the most effective technique leasing to approximately $80 \%$ recovery of the desulfurization conversion. while the reactivation by LGO at $320{ }^{\circ} \mathrm{C}$ slightly improved desulfurization activity and resulted in faster decrease of desulfurization conversion in the subsequent cycle. Moreover, higher temperatures led to better reactivation results due to the fact that high temperatures more effectively supported the thermal decomposition of 
DMDS at S-S and C-S bonds to various radicals responsible for sulfiding the catalyst surface (Vandeputte and Marin, 2010).

\section{Conclusions}

Deoxygenation of palmitic acid as a model of PFAD, in the presence of 4,6DMDBT as a sulfur-containing LGO was studied. The presence of palmitic acid in the model LGO, adversely affected desulfurization of 4,6-DMDBT. Slight decreases in the desulfurization of 4,6-DMDBT were observed when the mass percentage of palmitic acid were in the range of $0-10$ while further increases in the mass percentage of palmitic acid from 10 to 20 led to more pronounced decreases in the desulfurization conversion. On the hand, the addition of 4,6-DMDBT into the reaction medium stabilized the deoxygenation of palmitic acid resulting in high conversions $(>95 \%)$. At the temperature of $275{ }^{\circ} \mathrm{C}$, deoxygenation of palmitic acid and desulfurization of 4,6-DMDBT were stable within $48 \mathrm{~h}$ due to the decomposition of 4,6-DMDBT (producing $\mathrm{H}_{2} \mathrm{~S}$ ), while after $10 \mathrm{~d}(240 \mathrm{~h})$, the desulfurization conversion was significantly decreased. This was ascribed to a number of parameters, i.e., low reaction temperature and a significant pressure drop across the reactor. The latter was caused in response to the formation of heavy products as well as lack of available sulfur in the reactor. Moreover, a slight deactivation of the catalyst was observed at $275^{\circ} \mathrm{C}$. The catalyst was reactivated by sulfur-containing LGO and DMDS. Catalyst reactivation by 2 wt.\% of DMDS in n-C18 led to more favorable performance recovery and would be more practical in comparison with the sulfur-containing LGO.

\section{References}

[1] Badawi, M., Paul, J.F., Cristol, S., Payen, E., Romero, Y., Richard, F., Brunet, S., Lambert, D., Portier, X., Popov, A., Kondratieva, E., 2011. Effect of water on the stability of Mo and CoMo hydrodeoxygenation catalysts: a combined experimental and DFT study. J. Catal. 282(1), 155-164.

[2] Bezergianni, S., Dimitriadis, A., Kalogianni, A., Pilavachi, P.A., 2010. Hydrotreating of waste cooking oil for biodiesel production. Part I: effect of temperature on product yields and heteroatom removal. Bioresour. Technol. 101(17), 6651-6656.

[3] Boonyasuwat, S., Tscheikuna, J., 2017. Co-processing of palm fatty acid distillate and light gas oil in pilot-scale hydrodesulfurization unit over commercial CoMo / $\mathrm{Al}_{2} \mathrm{O}_{3}$. Fuel. 199, 115-124.

[4] Communication from the Commission to the European Parliament, the Council, the European Economic and Social Committee and the Committee of the Regions Energy 2020 A Strategy for competitive, sustainable and secure energy

[5] Egeberg, R., Michaelsen, N.H., Skyum, L., Topsoe, H., 2009. Novel hydrotreating technology for production of green diesel. 9-11.

[6] Graham-Wood, M., 2008. Catalyst Courier, Sustainable technology. 73.

[7] Hawash, S., El Diwani, G., Abdel Kader, E., 2011. Optimization of biodiesel production from jatropha oil by heterogeneous base catalysed transesterification. Int. J. Eng. Sci.Tech. 3(6), 5242-5251.

[8] Henke, J., 2017. Waste/Residue Classification and Double Counting in the Different EU Member States. ISCC System GmbH.

[9] Huber, G.W., Corma, A., 2007. Synergies between bio- and oil refineries for the production of fuels from biomass. Angew. Chem. Int. Ed. 46(38), 7184-7201

[10] Huber, G.W., Iborra, S., Corma, A., 2006. Synthesis of transportation fuels from biomass: chemistry, catalysts, and engineering. Chem. Rev.106 (9), 4044-4098.

[11] Huirache-acuña, R., Rivera-muñoz, E.M., Zepeda, T.A., Nava, R., Pawelec, B., 2016. Overview of phosphorus effect in molybdenum-based hydrotreating catalysts supported on ordered mesoporous siliceous materials, in: Sabet Dariani, R. (Ed.), Microporous Mesoporous Materials. In Tech.

[12] Isoda, T., Nagao, S., Ma, X., Korai, Y., Mochida, I., 1996. Hydrodesulfurization of refractory sulfur species. 1. Selective hydrodesulfurization of 4,6-dimethyldibenzothiophene in the major presence of naphthalene over $\mathrm{CoMo} / \mathrm{Al}_{2} \mathrm{O}_{3}$ and $\mathrm{Ru} / \mathrm{Al}_{2} \mathrm{O}_{3}$ blend catalysts. $10(2), 482-486$
[13] Iwamoto, R., Grimblot, J., 1999. Influence of phosphorus on the properties of Alumina-based hydrotreating catalysts. Adv. Catal 44, 417-503.

[14] Jẹczmionek, Ł., Porzycka-Semczuk, K., 2014. Hydrodeoxygenation, decarboxylation and decarbonylation reactions while co-processing vegetable oils over a NiMo hydrotreatment catalyst. Part I: thermal effects - theoretical considerations. Fuel. 131, 1-5.

[15] Kiatkittipong, W., Phimsen, S., Kiatkittipong, K. Wongsakulphasatch, S., Laosiripojana, N., Assabumrungrat, S. 2013. Diesel-like hydrocarbon production from hydroprocessing of relevant refining palm oil. Fuel Process. Technol. 116, 16-26.

[16] Kubicka, D., Horacek, J., 2011. Deactivation of HDS catalysts in deoxygenation of vegetable oils. Appl. Catal., A. 394(1-2), 9-17.

[17] Laurent, E., Delmon, B., 1994. Influence of water in the deactivation of a sulfided NiMoy- $\mathrm{Al}_{2} \mathrm{O}_{3}$ catalyst during hydrodeoxygenation. J. Catal. 146(1), 281-285, 288-291.

[18] Monnier, J., Tourigny, G., Soveran, D.W., Wong, A., Hogan, E.N., Stumborg, M., Canada Minister of Natural Resources, 1998. Conversion of biomass feedstock to diesel fuel additive. U.S. Patent $5,705,722$.

[19] Mikkonen, S., 2008. Second-generation renewable diesel offers advantages. Hydrocarbon Process. 87(2), 63-66.

[20] Renewable Energy Directive, 2009. Directive 2009/28/EC of the European Parliament and of the Council of 23 April 2009 on the promotion of the use of energy from renewable sources and amending and subsequently repealing Directives 2001/77/EC and 2003/30/EC. Off. J. Eur. Union. L140/17.

[21] Santillan-Jimenez, E., Crocker, M., 2012. Catalytic deoxygenation of fatty acids and their derivatives to hydrocarbon fuels via decarboxylation/decarbonylation. J Chem. Technol. Biotechnol. 87(8), 1041-1050.

[22] Snåre, M., Kubičková, I., Mäki-Arvela, P., Eränen, K., Murzin, D.Y. 2006. Heterogeneous catalytic deoxygenation of stearic acid for production of biodiesel. Ind. Eng. Chem. Res. 45(16), 5708-5715.

[23] Sotelo-boyás, R., Trejo-zárraga, F., Jesús Hernández-loyo F., 2012. Hydroconversion of triglycerides into green liquid fuels. In Hydrogenation. In Tech.

[24] Templis, C., Vonortas, A., Sebos, I., Papayannakos, N., 2011. Vegetable oil effect on gasoil HDS in their catalytic cohydroprocessing. Appl. Catal., B. 104(3-4)324-329.

[25] Toba, M., Abe, Y., Kuramochi, H., Osako, M., Mochizuki, T., Yoshimura, Y., Hydrodeoxygenation of waste vegetable oil over sulfide catalysts. Catal. Today. 164(1), 533-537.

[26] Vandeputte, A.G., Reyniers, M.F., Marin, G.B., 2010. Theoretical study of the thermal decomposition of dimethyl disulfide. J. Phys Chem. A. 114(39), 10531-10549.

[27] Viljava, T.R., 2001. From biomass to fuels: Hydrotreating of oxygencontaining feeds on $\mathrm{CoMo} / \mathrm{Al}_{2} \mathrm{O}_{3}$ hydrodesulfurization catalyst. $\mathrm{PhD}$ Dissertation, Helsinki University of Technology.

[28] Xu, Y., Shang, H., Zhao, R., Liu, C., 2004. The studies of hydrodesulfurization of 4,6-dimethyldibenzothiophene on sulfided $\mathrm{Mo} / \gamma-\mathrm{Al}_{2} \mathrm{O}_{3}$ : the effects of reactive temperature and pressure. Prepr. Pap. Am. Chem. Soc., Div. Fuel Chem. 49(1), 343-345. 